\title{
Predictors of undernutrition among the elderly in Sodo zuriya district Wolaita zone, Ethiopia
}

\author{
Kidest Wondiye ${ }^{1}$, Netsanet Abera Asseffa ${ }^{2^{*}}$ (D), Tsegaye Demisse Gemebo ${ }^{3}$ and Feleke Hailemichael Astawesegn ${ }^{2}$
}

\begin{abstract}
Background: In any society, the elderly are among the vulnerable and high risk groups with regard to health status. In persons over the age of 60 years, nutrition is among the important determinants of health. However, undernutrition among the elderly is often under diagnosed and/or neglected. Hence, in this study, we looked at prevalence and factors associated with undernutrition among the elderly.

Methods: A community based cross-sectional study was conducted at Sodo Zuriya district. Multi-stage systematic sampling method was used to select 578 elderly. A structured questionnaire was used to collect data on sociodemographics, dietary diversity, and health status of the elderly.

Measurements of weight and height were taken using digital weighing scale and stadio-meter, respectively. Data was entered and cleaned in Epi-Data version3.1 and exported to SPSS version 20 for analysis. Binary and multivariate logistic regressions were done and odds ratios with 95\% confidence intervals were calculated.

Results: The overall prevalence of undernutrition was $17.1 \%$. On multivariate logistic regression, being unable to read and write $(A O R=2.09)$, not being married $(A O R=2.02)$, history of decline in food intake $(A O R=2.1)$, smoking $(A O R=4.9)$ and monthly income $<\$ 20(A O R=7.5)$ were factors positively associated with undernutrition.

Conclusion: The study revealed that prevalence of undernutrition in the district was relatively high. Hence, it is among the major public health burdens in the district. Hence, to improve nutritional status of elderly the district health office and health professionals should consider behavioral support interventions to assist in cessation of smoking. There is also a need to financially empower the elderly in the district.
\end{abstract}

Keywords: Elderly, Undernutrition, Associated factors, Southern Ethiopia

\section{Background}

Aging is an irreversible biological process which starts from conception and ends after death [1].. The world has seen substantial growth in the number of the elderly population and expected to become the largest demographic group in many countries in the next few decades. According to the United Nations, in 2025, it is estimated that the number of aged people 60 years or older will be 1.2 billion and 2 billion in 2050 representing about $22.0 \%$ of the world's population [2]. Eleven percent of the world population and $5.0 \%$ of Ethiopian population were categorized under elderly

\footnotetext{
*Correspondence: aberanet@gmail.com

${ }^{2}$ School of Public Health, College of Health Sciences and Medicine, Hawassa University, Hawassa, Ethiopia

Full list of author information is available at the end of the article
}

population- aged $\geq 60$ years [3, 4]. The rising life expectancy within the older population responsible for their number and proportion at old ages [5].

Malnutrition is the state of being poorly nourished which can be caused by excess (overnutrition) or lack of nutrients (undernutrition). In the aging group undernutrition is an important problem that has been seen in hospitals, residential care and in the community [6]. The prevalence of undernutrition is increasing among the elderly and associated with a decline in functional status, impaired muscle function, decreased bone mass, immune dysfunction, anemia, reduced cognitive function, poor wound healing, delayed recovery from surgery, higher hospital readmission rates, severe, morbidity and mortality [7]. 
Studies determining the prevalence of undernutrition among elderly shows prevalence ranges from 0 to $24.0 \%$ [8-10]. The overall prevalence of under nutrition among older people in sub-Saharan Africa is reported to be between $6 \%$ in Cameroon, and $48.0 \%$ in Ghana. Older age group were more affected by malnutrition than their counter parts $[11,12,14-16]$.

Undernutrition among elderly people is becoming significantly high regardless of the better progress on health care system. In a study done in Northwest Ethiopia, the prevalence of under nutrition among elderly people was $21.9 \%$ [3]. In Ethiopia, little attention has been given to the elderly despite their increasing number and nutritional needs. However, there are limited studies which assess the determinants of under nutrition in elderly people in southern Ethiopia. Therefore, the aim of this study was to determine the prevalence of undernutrition and to identify risk factors associated with undernutrition among elderly.

\section{Methods}

\section{Study design and area}

A community based cross sectional study design was employed in Sodo Zuriya district from February to June, 2017. Sodo Zuriya district was one of the districts in Wolaita Zone, Southern Ethiopia. It is located at $327 \mathrm{Kms}$ (Kilometers) far from Addis Ababa, capital city of Ethiopia and $160 \mathrm{Kms}$ from Hawassa, the regional capital. Based on the last census, it had a total population of 162,691, of whom 80,002 were men and 82,689 women. The number of older persons - those aged 60 years or over were 16,233. The district had 36 Kebeles (the smallest administrative unit in Ethiopia) [12]. The major type of cereal grow in the district was maize. The population mostly consumes root and tuber based products like potato, sweet potato, godere ( $a$ greenish-purple potato), and cassava. Among fruits avocado, papaya, banana and mango were commonly consumed. From vegetables kale and cabbage were frequently used.

\section{Study population}

Study population were elderly who were systematically selected and living in selected Kebeles of the Sodo Zuriya district. Those who were seriously ill and who cannot stand without aid were excluded from the study. Five participants were excluded from the study.

\section{Sample size determination and sampling technique}

The sample size was calculated using a single population proportion formula,

$$
n=\frac{z_{1-\alpha / 2}^{2} p(1-p)}{d^{2}}
$$

The assumptions were, estimated prevalence for undernutrition of elderly, $21.9 \%$ from study done in
Gonder town [3], margin of error 5.0\%, design effect of 2 and $10.0 \%$ non-response rate. Accordingly, the final sample size became 578. A multi stage simple random sampling technique were applied to select ten kebeles out of 36 kebeles.. In the selected 10 kebeles there were 207 subKebeles. Then we considered a proportional allocation to the sample size to allocate participant for each sub-Kebeles, finally systematic sampling technique was used to select households included in the study. The sampling interval was calculated by dividing the total households in the selected sub-Kebeles of the Kebele by the final sample size, which gave every third household. Then after, the first household was selected from each sub-Kebeles, by spinning a pen, where the tip of the pen was pointed taken to be the first household. Then the sampling interval was added on to the first household to identify the consecutive households.

\section{Data collection tool}

The questionnaires contains socio-demographic factors, life style factors, $24 \mathrm{~h}$ food diary and nutritional factors, physiological factors, psychological factors and health related factors. During the preparation of the questionnaire, related published articles and Mini Nutritional Assessment Questionnaire were reviewed and contextualized. It was prepared in English and translated into Amharic and back translated into English to maintain consistency.

\section{Data quality assurance}

Before actual data collection pre-test was done among $10 \%$ of sample size in relatively similar district but out of actual study area to check accuracy, to estimate time and any inconsistency and necessary corrections were made. Experts with a nutrition and dietetic background assessed content validity. Trained ten diploma holders in clinical nursing collected data and two bachelor holders supervised the collection. The data collection tool had two parts; interview using questionnaire and target population assessment using measurement scales. Regarding the target population assessment, weight and height were measured using digital weighing scale and Stadio-meter respectively. During the measurement participants were barefoot, legs straight, shoulders relaxed and look straight ahead at the horizontal plane. In addition, they were asked to inhale deeply, hold the breath and maintain an erect position just before taking the measurement. Reading of height measurement was taken twice to the nearest $0.1 \mathrm{~cm}$. A digital weighing scale was used to measure weight; it was measured twice in light clothes without shoes and stand still in the middle of the scale's platform; and the average weight was taken. The district grows most of the stable crops through out the year. Hence, the difference might not exist when it comes to when data was collected. 


\section{Operational definition \\ Seriously ill}

Those who were unable to communicate due to sickness were considered as seriously sick. Moreover, this study involved height measurement that requires being on barefoot, legs straight; shoulders relaxed and maintain an erect position. Those who were unable to do so were also excluded.

Elderly: a person whose age greater than 60 years [13].

\section{Undernutrition}

Elderly who had BMI less than $18.5 \mathrm{~kg} / \mathrm{m}^{2}$. Those who had Body Mass Index (BMI) between $18.5 \mathrm{Kg} / \mathrm{m}^{2}$ to 24.9 $\mathrm{Kg} / \mathrm{m}^{2}$ were considered as normal and between 25 and $29.9 \mathrm{Kg} / \mathrm{m}^{2}$ were considered as overweight and obese and coded as No whereas those with BMI of less than $18.5 \mathrm{Kg} /$ $\mathrm{m}^{2}$ considered as undernutrition and coded as Yes [14].

The food groups' classification were determined using the Food and Nutrition Technical Assistance (FANTA) description as Low Dietary Diversity Score (DDS): when an elderly person consume $<3$ food items per day; Moderate Dietary Diversity Score (DDS): when an elderly consume $4-5$ food items per day; High Dietary Diversity Score (DDS): when an elderly consume $>5$ food items per day [15].

\section{Malnutrition}

We classified malnutrition using Subjective Global Assessment form (SGA). Which is validated tool to classify malnutrition clinically. Accordingly Mild under nutrition: no decrease in food/nutrient intake; $<5 \%$ weight loss; no/minimal symptoms affecting food intake; no deficit in function; Moderately malnourished: definite decrease in food/nutrient intake; $5-10 \%$ weight loss without stabilization or gain; mild/some symptoms affecting food intake; Severely malnourished: severe deficit in food/nutrient intake; >10\% weight loss which is ongoing; significant symptoms affecting food/ nutrient intake; severe functional deficit.

Cigarette smoking: was operationalized as subjects who smoked at least one cigarette per day at the time of the study was classified as current smokers and those who smoked for at least three years in the past but had stopped by the time of the study was classified as a habitual smokers. Got was defined as a block or village that contains minimum thirty households.

\section{Method of analysis}

Data were entered into Epi-Data version 3.1 and exported to SPSS version 20 for analysis. All continuous data were checked for normality using histogram and other normal plots. Univariate analysis was used to determine the frequencies. Bivariate analysis was applied to determine associations between outcome and exposure variables. Independent variables having $P$-value less than 0.05 on bivariate analysis were candidates for multivariable analysis for further confounding effect control.
Hosmer and Lemeshew goodness of fit test was done to assess the fitness of the model during multivariate analysis. With $p$-value of 0.25 , the model was ensured being fit well for the multivariate analysis and accepted. Both crude and adjusted odds ratio with 95\% confidence interval were reported to measure the strength of association between exposure and outcome variable. The results on multiple logistic regression were considered statistically significant at $P$-value $<0.05$.

\section{Results}

Socio demographic characteristics of participants

Of the total 578, 554 elderly participated in the study giving response rate of $96.0 \%$. The median age of participants was 65 years with $(S D \pm 8.1)$. Among the study participants majority of them were aged $60-65$ years, $52.2 \%$ $(n=281)$. Majority of the participants, 76.5\% $(n=424)$ cannot read and write. Most of the participants, $83.0 \%$ $(n=460)$ had monthly income less than $\$ 20$ (Table 1).

\section{Health and life style characteristics of participants}

Regarding cigarette smoking and alcohol intake, 79.4\% $(n=31)$ smoke on daily basis and $27.5 \%(n=27)$ took alcohol on daily basis. Regarding health status of the participants, $49.3 \%(n=273)$ were sick in the last three months. From the total participants, $33.6 \%(n=183)$ of them were suffering from decline in food intake in the last three months and most mentioned loss of appetite as a reason. Of the total participants, $81.8 \%(n=453)$ of participants do not feel lonely (Table 2).

\section{Food frequency and dietary diversity characteristics}

The most commonly consumed food groups in the last $24 \mathrm{~h}$ were dark green vegetables $(81.9 \%)$, followed by

Table 1 Socio-demographic characteristics of elderly in Sodo Zuriya districts, Wolaita zone, southern Ethiopia $2017(n=554)$

\begin{tabular}{|c|c|c|c|}
\hline Variable & Category & $\mathrm{N}$ & $\%$ \\
\hline \multirow[t]{2}{*}{ Sex } & Male & 295 & 53.2 \\
\hline & Female & 259 & 46.8 \\
\hline \multirow[t]{3}{*}{ Age group } & $60-65$ & 281 & 52.2 \\
\hline & $66-79$ & 195 & 35.2 \\
\hline & $>80$ & 70 & 12.6 \\
\hline \multirow[t]{5}{*}{ Religion } & Orthodox & 274 & 49.5 \\
\hline & Protestant & 255 & 46 \\
\hline & Catholic & 15 & 2.7 \\
\hline & Muslim & 6 & 1.1 \\
\hline & Apostolic & 4 & 0.7 \\
\hline \multirow[t]{3}{*}{ Education status } & Unable to read and write & 424 & 76.5 \\
\hline & Primary & 99 & 17.9 \\
\hline & Secondary and above & 31 & 5.6 \\
\hline
\end{tabular}


Table 2 Health and Life style characteristics of elderly in Sodo Zuriya districts, Wolaita zone, southern Ethiopia 2017 ( $n=554)$

\begin{tabular}{|c|c|c|c|}
\hline Variable & Category & $n$ & $\%$ \\
\hline \multirow[t]{2}{*}{ Currently smoking } & Yes & 39 & 7.0 \\
\hline & No & 515 & 93.0 \\
\hline \multirow[t]{2}{*}{ Smoke daily $(n=39)$} & Yes & 31 & 79.4 \\
\hline & No & 8 & 20.6 \\
\hline \multirow[t]{2}{*}{ Drink alcohol currently } & Yes & 98 & 17.7 \\
\hline & No & 456 & 82.3 \\
\hline \multirow[t]{5}{*}{ Frequency of alcohol use } & Daily & 27 & 27.5 \\
\hline & 5-6 days per week & 22 & 22.4 \\
\hline & 1-4 days per week & 16 & 16.3 \\
\hline & $1-3$ days per month & 25 & 25.5 \\
\hline & Once per month & 8 & 8.2 \\
\hline \multirow[t]{2}{*}{ Illness in the last three months } & Yes & 273 & 49.3 \\
\hline & No & 281 & 50.7 \\
\hline \multirow[t]{4}{*}{ Frequent disease occurred } & Joint pain & 167 & 30.1 \\
\hline & Hypertension & 40 & 7.2 \\
\hline & Diabetes mellitus & 19 & 3.4 \\
\hline & Others $^{a}$ & 47 & 8.5 \\
\hline \multirow[t]{2}{*}{ Decline in food intake } & Yes & 183 & 33.0 \\
\hline & No & 371 & 67.0 \\
\hline \multirow[t]{4}{*}{ Reason for decline } & Digestive problem & 51 & 27.7 \\
\hline & Loss of appetite & 86 & 47.0 \\
\hline & Chewing problem & 28 & 15.3 \\
\hline & Loss of smell and taste & 18 & 9.8 \\
\hline \multirow[t]{2}{*}{ Take medication currently } & Yes & 118 & 21.3 \\
\hline & No & 436 & 78.8 \\
\hline \multirow[t]{3}{*}{ Reason for loneliness } & Loss of family member & 56 & 10.1 \\
\hline & Social isolation & 27 & 4.9 \\
\hline & Other $^{b}$ & 19 & 3.4 \\
\hline
\end{tabular}

${ }^{a}$ Acute febrile illness, skin diseases, ${ }^{b}$ loss of assets

dairy products $(60.6 \%)$ and legumes and nuts (54.5\%). Regarding the dietary diversity score (DDS), 57.0, 28.0 and $15.0 \%$ scored low, moderate and high respectively (Table 3 ).

\section{Prevalence of undernutrition}

The overall prevalence of undernutrition among elderly in Sodo Zuriya districts was $17.1 \%$ while majority $80.6 \%$ $(n=446)$ have normal BMI and only $2.3 \%(n=13)$ of them were overweight. Among the undernourished subjects $11.0 \%(n=61)$ of them fall under mild category, $5.0 \%(n=27)$ at moderate and $1.1 \%(n=7)$ of them fall under severe category. The prevalence of undernutrition was slightly high among females $20.5 \%$ compared to male $14.2 \%$. The prevalence is also relatively high among study participants whose age are greater than 65 years
Table 3 Consumption of the nine food groups by the study subjects in the last $24 \mathrm{~h}$ at Sodo Zuriya districts, Wolaita zone, southern Ethiopia $2017(n=554)$

\begin{tabular}{llll}
\hline Variable & Categories & $\mathrm{n}$ & $\%$ \\
\hline Any cereal and root & Yes & 234 & 42.2 \\
Any dark green vegetables & No & 320 & 57.8 \\
Other vitamin A rich fruits and vegetables & Yes & 454 & 81.9 \\
& No & 100 & 18.1 \\
Other fruits and vegetables & No & 207 & 37.4 \\
& Yes & 259 & 46.6 \\
Meat or fish & No & 295 & 53.2 \\
Organ meat & Yes & 232 & 41.9 \\
& No & 322 & 58.1 \\
Legumes and nuts & Yes & 221 & 39.9 \\
& No & 333 & 60.1 \\
Milk and milk products & Yes & 302 & 54.5 \\
Egg & No & 252 & 45.5 \\
Dietary diversity score & Yes & 336 & 60.6 \\
& No & 218 & 39.4 \\
& Yes & 83 & 15.0 \\
& No & 471 & 85.0 \\
& High & 83 & 15.0 \\
& Moderate & 155 & 28.0 \\
& Low & 316 & 57.0 \\
\hline
\end{tabular}

$24.6 \%$ than those whose age are between 60 and 65 years $14.8 \%$.

\section{Independent predictors of undernutrition among the elderly}

On bivariate logistic regression, factors such as age group, being unable to read and write status, sex, not being married, illness in the last three month, weight lost, taking medication, decline in food intake, smoking and monthly income $<\$ 20$ were positively associated with undernutrition. Whereas, on the multivariable logistic regression, being unable to read and write, not being married, decline in food intake, monthly income $<\$ 20$ and smoking were positively associated with undernutrition (Table 4).

Elderly who cannot read and write were two times more likely to be undernourished than those who can read and write $(\mathrm{AOR}=2.09,95 \% \mathrm{CI}$ : 1.02-4.2). Study participants whose marital status either widowed or divorced were two times more likely to be undernourished than those married (AOR $=2.02,95 \% \mathrm{CI}: 1.2-3.4$ ). This study also showed that elderly who have history of decline in food intake had 2.1 times odds of being undernourished than their counter parts $(\mathrm{AOR}=2.1,95 \% \mathrm{CI}$ : 1.02-4.2). Those who smoke on daily basis were five 
Table 4 Bivariate and multivariate logistic regression of factors associated with undernutrition among elderly at Sodo Zuriya districts, Wolaita Zone, southern Ethiopia, $2017(n=554)$

\begin{tabular}{|c|c|c|c|c|c|}
\hline \multirow[t]{2}{*}{ Variable } & \multirow[t]{2}{*}{ Category } & \multicolumn{2}{|c|}{ Undernutrition } & \multicolumn{2}{|l|}{$\underline{95 \% \text { C. I for OR }}$} \\
\hline & & Yes (\%) & No (\%) & Bivariate (COR) & Multivariate (AOR) \\
\hline \multirow[t]{2}{*}{ Age group } & $60-79$ & $62(14.8)$ & $358(85.2)$ & 1 & \\
\hline & $>80$ & $33(24.6)$ & $101(75.4)$ & $1.6[0.33-0.83]^{* *}$ & $0.7(0.42-1.25)$ \\
\hline \multirow[t]{2}{*}{ Read \& Write } & Unable & $84(19.8)$ & $340(80.2)$ & $2.3[1.37-5.21]^{* *}$ & $.2 .09(1.02-4.27)^{* * *}$ \\
\hline & Able & $11(8.5)$ & $119(91.5)$ & 1 & \\
\hline \multirow[t]{2}{*}{ Smoke currently } & Yes & $7(43.8)$ & $9(56.2)$ & $3.9[1.43-10.92]^{* *}$ & $4.9(1.53-15.45)^{* * *}$ \\
\hline & No & $88(16.4)$ & 450 (83.6) & 1 & \\
\hline \multirow[t]{2}{*}{ Sex } & Female & $53(20.5)$ & $206(79.5)$ & $1.4[0.4-12.07]^{* *}$ & $0.9(0.55-1.53)$ \\
\hline & Male & $42(14.2)$ & $253(85.8)$ & 1 & \\
\hline \multirow[t]{2}{*}{ Illness in the last three month } & Yes & $57(20.9)$ & $216(79.1)$ & $1.5[1.07-2.64]^{* *}$ & $1.3(0.67-2.56)$ \\
\hline & No & $38(13.5)$ & $243(86.5)$ & 1 & \\
\hline \multirow[t]{2}{*}{ Weight lost in the last three month } & Yes & $30(23.6)$ & $97(76.4)$ & $1.5[1.06-2.88]^{* *}$ & $1.2(0.53-2.12)$ \\
\hline & No & $65(15.2)$ & $362(84.8)$ & 1 & \\
\hline \multirow[t]{2}{*}{ Marital status } & Married & $44(12.3)$ & $314(87.7)$ & 1 & \\
\hline & Others* & $51(26.0)$ & $145(74)$ & $2.1[0.25-0.66]^{* *}$ & $2.02(1.26-3.43) * * *$ \\
\hline \multirow[t]{2}{*}{ Take medication currently } & Yes & $27(22.9)$ & $91(77.1)$ & $1.5[0.92-2.65]^{* *}$ & $1.2(0.63-2.35)$ \\
\hline & No & $68(15.6)$ & $368(84.4)$ & 1 & \\
\hline \multirow[t]{2}{*}{ Decline food intake } & Yes & $47(25.7)$ & $136(74.3)$ & $1.9[1.48-3.66]^{* *}$ & $2.1(1.02-4.23)^{* * *}$ \\
\hline & No & $48(12.9)$ & $323(87.1)$ & 1 & \\
\hline \multirow[t]{2}{*}{ Monthly income (\$) } & $<20$ & $92(20.0)$ & $368(80.0)$ & $7.5[2.35-24.42]^{* *}$ & $7.5(2.12-26.56)^{* * *}$ \\
\hline & $>20$ & $3(3.2)$ & $91(96.8)$ & 1 & \\
\hline
\end{tabular}

*Divorced or Widowed, ${ }^{* *} p$-value $<0.25,{ }^{* * *} p$ value $<0.05$

times $(\mathrm{AOR}=4.9,95 \% \mathrm{CI}: 1.5-15.4)$ more likely to be undernourished than those who do not. Elderly whose monthly income less than 500 ETB (Ethiopian Birr) (\$20) was 7.5 times $(\mathrm{AOR}=7.5,95 \% \mathrm{CI}$ : 2.1-26.5) high likely to be undernourished than their counterparts (Table 4).

\section{Discussion}

The overall prevalence of undernutrition was $17.1 \%$. The prevalence was high among females $20.5 \%$ compared to males $14.2 \%$. This finding is comparable with the studies done in northwest Ethiopia where 21.9\%, Ghana $18.0 \%$ and Derham city of India (21.8\%) were undernutrition $[1,3]$. And it was lower as compared to study done in Tamil Nadu of India (41.3\%), Brazil (28.9\%) and lake Victoria basin of Tanzania (26.4\%) [16-18]. However, it was higher than that of the study conducted in southwest Nigeria 2.9\% [23]. The difference could be due to variation in socio-economic status of study population and some of the studies focused on urban dwellers.

This study pointed out that $57.0 \%$ of the elderly had low dietary diversity score. This finding is higher than a cross sectional study done in Northwest Ethiopia [1]. This difference might be related to the fact that their study was conducted in urban settings where people are less affected by poverty and food insecurity.

In this study, being unable to read and write were 2.09 times $(\mathrm{AOR}=2.09,95 \% \mathrm{CI}: 1.02-4.2)$ more likely to be undernourished than those who can read and write. This is similar in other reported studies; Bangladesh and elderly of Lebanese living in rural settings $[3,8,19]$. The reason might be that knowledge has contribution for ones individual to consume diversified food and educated people are more likely to have good feeding practice and better life style.

Being widowed or divorced were two times was found to be an independent predictor of undernutrition. The result was similar to those in previous reports in Ghana and Portugal $[20,21]$ where majority of the study participants were married and had normal BMI while widowed or single were found to be underweight. The similarity might be related to exposure the elderly social isolation, loneliness, depression, financial worries that will affect food intake as a result increase likelihood of being undernourished.

In our study, decreased food intake was positively associated with undernutrition as compared to their counterpart. This finding is in-line with reports from Finland and India which illustrated significant relationship between nutritional status and declining food intake [22- 
24]. This might be related to increased age which in turn reduce the natural drive to eat and drink and resulting in anorexia of aging. These age related changes are regarded as an adaption to the natural decrease in energy requirement but also predispose older people to malnutrition by increasing the risk of an extreme reduction in food intake.

Another positively associated factor to develop undernutrition was cigarette smoking. This shows that unhealthy life style affect nutritional status of elderly as supported by a study conducted in northern Ghana where use of tobacco or cigarette smoking had effect on lowering BMI of the elderly [20]. In addition, smoking compromises the need to take food as well as fruits and vegetable that are rich in vitamin $\mathrm{c}$ and carotene.

Moreover, monthly income of less than $\$ 20$ had significant association with undernutrition; similar to studies done in India and France which showed low income has negative effect on nutrition status of elderly [23-25]. This proves that nutrition-related health is closely related to socioeconomic status. Limited money may mean older people choose foods they would prefer not to eat. Being unable to afford and inadequate food intake could lead to poor nutritional status in elderly [26].

The findings of this study are generalizable to the region's population because the participants' socio-economic, educational status and way of life is unbiased reflection of the southern region elderly population [27]. This study has its own limitations. Information obtained from elderly on their health status, socio-demographic background, life style and their dietary intake might have recall bias. Since this study used physical measurements, there was probability of measurement and instrument error; as age increase there will be progressive and generalized loss of skeletal muscle and decrease bone height and density which affects their BMI during physical measurement which might over estimated prevalence of undernutrition in this study. Moreover, not examining oral, dental factors and data whether they own land or not was collected were limitations.

\section{Conclusion}

The overall prevalence of undernutrition among the elderly in the district was relatively high. Undernutrition is therefore an important public health burden among the elderly in the study area. Being unable to read and write, not being married, decline in food intake, monthly income $<\$ 20$ and being smoker currently on daily basis were factors positively associated with undernutrition.

Hence, to improve nutritional status of elderly the district health office and health professionals should consider behavioral support interventions to assist in cessation of smoking, and socialization with others.. There is also a need to financially empower the elderly in the district. Further studies are needed to generate a database for effective policy making and formulate a national policy on the nutrition and health of the elderly targeting the whole population to ensure healthy aging.

\section{Abbreviations}

AOR: Adjusted Odds Ratio; BMI: Body Mass Index; Cl: Confidence Interval; COR: Crude Odds Ratio; DDS: Dietary Diversity Score; ETB: Ethiopian Birr; FANTA: Food and Nutrition Technical Assistance

\section{Acknowledgments}

The authors acknowledge the study participants, the school authorities, and Wolaita Sodo University.

\section{Authors' contributions}

KW conceived, designed and conducted the study. TDG, FHA, and NAA consulted the overall process of the study. All the authors read and approved the final content of the manuscript.

\section{Funding}

The study was financially supported by Wolaita Sodo University in collaboration with Norwegian Aid Organization. However, it had no role in the design of the study, interpretation of the data, the collection, analysis, and interpretation of the data, or the writing of the manuscript.

\section{Availability of data and materials}

The dataset analysed for the findings of this study are available with the corresponding author and can be accessed by reasonable request.

\section{Ethics approval and consent to participate}

Ethical approval was obtained from Wolaita Sodo University ethical review committee. Permission was obtained from relevant quarters before actual data collection. Written consent was obtained from each participant.

Consent for publication

Not applicable.

\section{Competing interests}

The authors declare that they have no competing interests.

\section{Author details}

${ }^{1}$ Terepeza Development Association (TDA), Wolaita District Office Project Facilitator, Wolaita sodo, Ethiopia. ${ }^{2}$ School of Public Health, College of Health Sciences and Medicine, Hawassa University, Hawassa, Ethiopia. ${ }^{3}$ School of Public Health, College of Health Sciences and Medicine, Wolaita Sodo University, Wolaita sodo, Ethiopia.

Received: 24 September 2018 Accepted: 1 November 2019 Published online: 08 November 2019

\section{References}

1. Kritika S, Jayanti Semwal SV, SH JR. Nutritional status and associated comorbidities among the elderly in Doiwala block, Dehradun. Indian J Community Health. 2014;26(2):7.

2. NU-AGE. New dietary strategies addressing the specific needs of elderly population for an healthy ageing in Europe. Italy; 2016. https://www.wur.nl/ en/show/nuage.htm. Accessed June 2017

3. Tessfamichael D, Gete AA, Wassie MM. High prevalence of Undernutrition among elderly people in Northwest Ethiopia: a cross sectional study. J Nutr Health Food Sci. 2014:2(4):1-5.

4. Ashenafi GAM. Aging and Retirement among Ethiopian Elderly: Adjustment, Challenges and Policy Implications, vol. 06: Addis Ababa University Institutional Repository. Addis Ababa University; 2015.

5. National Institute on Aging U. Global Aging. NIH Public Access. 2015 [cited Sept 11, 2017].

6. Hickson M. Malnutrition and ageing. BMJ Postgrad Med J. 2006;82(963):2-8.

7. Amarya S, Kalyani Singh MS. Changes during aging and their association with malnutrition. J Clin Gerontol Geriatr. 2015;6(3):78-84.

8. Boulos C, Salameh P, Barberger-G P. The AMEL study, a cross sectional population-based survey on aging and malnutrition in 1200 elderly Lebanese living in rural settings: protocol and sample characteristics. BMC Public Health. 2013;13(573). https://doi.org/10.1186/1471-2458-13-573. 
9. Schilp J, Kruizenga HM, Wijnhoven HAH, Leistra E, Evers AM, van Binsbergen $\mathrm{JJ}$, et al. High prevalence of undernutrition in Dutch community-dwelling older individuals. Nutrition. 2012;28(11-12):1-6.

10. Je'sus $\mathrm{P}$, et al. Under nutrition and obesity in two cities in developing countries: prevalence and associated factors in the EDAC study. Clin Nutr ESPEN. 2017;21:40-50.

11. Mahfouz EM, Mohammed ES, Abd El-Rhman TA. Assessment of nutritional status of elderly populations in rural Minia, Egypt. Minia, Egypt: Minia University. J Aging Res Clin Practice. 2014;2(3):300-2.

12. Sodo Zuriya district. Annual Health and related data report. 2016.

13. World Health organization. Health Situtation and trend assessment- Elderly Population. Available on http:/www.searo.who.int/entity/health_situation_ trends/data/chi/elderly-population/en/ Last accessed on 12 Aug 2019

14. Flegal KM, Kit BK, Graubard BI. Body mass index categories in observational studies of weight and risk of death. Am J Epidemiol. 2014;180(3):288-96.

15. Vaitla B, Coates J, Maxwell D. Comparing household food consumption indicators to inform acute food insecurity phase classification. Washington DC: FHI 360/Food and Nutrition Technical Assistance III Project (FANTA); 2015.

16. Cheserek MJ, Tuitoek PJ, Waudo JN, Msuya J, Kikafunda JK. Anthropometric characteristics and nutritional status of older adults in the Lake Victoria Basin of East Africa:region, sex, and age differences. S Afr J Clin Nut. 2012; 25(2):67-72

17. Bayapa Reddy N, Reddy LKV, Pallavi M, Reddy N, Sireesha P. A Study on nutritional status and prevalence of non communicable diseases among the rural elderly of Tamil Nadu: a community based cross sectional study. Int J Res Health Sci. 2014;30(2):604-9.

18. Fares D, Barbosa AR, Borgatto AF, Coqueiro Rda S, Fernandes MH. Factors associated with nutritional status of the elderly in two regionsof Brazil. Rev Assoc Med Bras. 2012;58(4):434-41.

19. Kabir ZN, Ferdous T, Cederholm T, Khanam MA, Streatfied K, Wahlin A. Mini nutritional assessment of rural elderly people in Bangladesh: the impact of demographic, socioeconomic and health factors. Public Health Nutr. 2006; 9(8):968-74.

20. Aganiba BA, Owusu WB, Steiner-Asiedu M, Dittoh S. Association between lifestyle and health variables with nutritional status of the elderly in the Northern Region of Ghana. Afr J Food Agric Nutr Dev. 2015;15(4):10198-216.

21. Luisa SA, Maria T, Pedro N. Undernutrition and associated factors in a Portuguese older adult community. Bras J Nutr. 2015;28(3):231-40.

22. Johansson Y, Bachrach-Lindstro M, Carstensen JA-C. Malnutrition in a homeliving older population: prevalence, incidence and risk factors. A prospective study. J Clin Nurs. 2008;18(9):1354-64.

23. Agarwalla R, Saikia A, Baruah R. Assessment of the nutritional status of the elderly and its correlates. J Fam Community Med. 2015;22(1):39-43.

24. Satu J. Nutrition of older people and the effect of nutritional interventions on nutrient intake, diet quality and quality of life. Finland: University of Helsinki; 2016. https:/helda.helsinkifi/bitstream/handle/10138/160518/NUTRITIO.pdf.

25. Torres Marion J, Dorigny B, Letenneur L. Nutritional Status in CommunityDwelling Elderly in France in Urban and Rural Areas. PloS One. 2014;9(8): e105137. https://doi.org/10.1371/journal.pone.0105137.

26. Ministry of Health. Food and Nutrition Guidelines for Healthy Older People: A background paper. Wellington: Ministry of Health; 2013.

27. Central Statistical Agency (CSA) [Ethiopia] and ICF. 2016. Ethiopia Demographic and Health Survey 2016. Addis Ababa, Ethiopia, and Rockville, Maryland, USA: CSA and ICF.

\section{Publisher's Note}

Springer Nature remains neutral with regard to jurisdictional claims in published maps and institutional affiliations.

Ready to submit your research? Choose BMC and benefit from:

- fast, convenient online submission

- thorough peer review by experienced researchers in your field

- rapid publication on acceptance

- support for research data, including large and complex data types

- gold Open Access which fosters wider collaboration and increased citations

- maximum visibility for your research: over $100 \mathrm{M}$ website views per year

At $\mathrm{BMC}$, research is always in progress.

Learn more biomedcentral.com/submissions 